\title{
EXPLORING THE INTEGRATION OF THE POWER TO GAS TECHNOLOGIES AND THE SUSTAINABLE TRANSPORT
}

\author{
E. LLERA ${ }^{1}$, L. M. ROMEO ${ }^{1}$, M. BAILERA ${ }^{1} \&$ J. L. OSORIO ${ }^{2}$ \\ ${ }^{1}$ Escuela de Ingeniería y Arquitectura, Departamento de Ingeniería Mecánica, Universidad de Zaragoza, \\ Campus Río Ebro, María de Luna, Zaragoza, Spain. \\ ${ }^{2}$ CIRCE Institute -Universidad de Zaragoza, CIRCE Building - Campus Río Ebro, \\ Mariano Esquillor Gómez, Zaragoza, Spain.
}

\begin{abstract}
The de-carbonization of the transport sector is a particularly complex challenge as greenhouse gases are delocalized and diffused. Therefore, the problem has to be tackled from the source of the emissions, and efforts in the scientific and technological field must seek out new energy vectors of high density, neutral in $\mathrm{CO}_{2}$ and based on renewable energy that meet the sector demands and requisites. This could be the case of the synthetic natural gas which can be produced through the Power to Gas process (PtG). This process, originally developed by the German institutes ZSW and IWES, converts electricity into synthetic natural gas (SNG) via the methanation of $\mathrm{CO}_{2}$ together with $\mathrm{H}_{2}$ from water electrolysis. The energy content of the produced methane comes from the primary source for power generation (optimally renewable electricity) and it is possible to produce a $\mathrm{CO}_{2}$ neutral fuel by capturing the carbon emissions from an existing source. In addition, the PtG process can be seen as a new concept of renewable energy and $\mathrm{CO}_{2}$ hybrid storage. This paper identifies the possibilities that the Power to Gas technology offers for the production of sustainable methane and the existing potential for the symbiosis of industrial sectors through optimization of their waste streams of matter and energy. In particular power and transport sectors are considered and the outline of a small facility for the generation of synthetic natural gas from renewable electricity and its consumption in the vehicles of a road freight company is presented as a case study. Not only the technical feasibility but the economic viability of the process and the environmental improvements resulting from the use of a renewable fuel free of $\mathrm{CO}_{2}$ emissions in terms of carbon footprint are evaluated.
\end{abstract}

Keywords: alternative fuels, carbon capture, energy storage, Power-to-gas, synthetic natural gas.

\section{INTRODUCTION}

In order to improve the security of the European energy supply and reduce the emissions of greenhouse gases (GHG), the European Union (EU) set in 2001 the objective of replacing $20 \%$ of conventional fuels by 2020 through the introduction of liquid biofuels in the short term, natural gas (NG) in the medium and long term and hydrogen in the distant long term [1]. In addition, it was expected that biofuels shared at least $6 \%$ of the fuels used in road transport in 2010. However, biofuels only shared $4.4 \%$ by 2010 [2], which was mainly the result of socioeconomic problems generated in Europe and in developing countries by the production of feedstocks, such as an increase in food prices and land use competition [3]. For that reason, the European Commission (2013) recommended different alternative fuels based on the maturity of the technologies for each application, such as electricity, compressed natural gas (CNG) and hydrogen, for urban use vehicles and liquefied natural gas (LNG) for long-haul transport.

It is broadly agreed that electric vehicles powered by renewable energy vectors (battery electric vehicles (BEVs) for renewable electricity or fuel cell electric vehicles (FCEVs) for renewable hydrogen) can help EU towards a more sustainable transport system and meeting its goal to reduce greenhouse gas emissions by $80-95 \%$ by 2050 [4]. However, larger numbers of electric vehicles will not be enough for the shift to a low-carbon economy and in the short and medium term, it is clear that Europe will still have to rely on conventional internal combustion engine vehicles (ICEVs), while new and cleaner technologies develop. 
In the meanwhile, the natural gas can play a bridging role as it can be used both in spark-ignition and in compression-ignition engines [5]. NG has been widely and profitably applied in compressed form in many countries mainly in urban vehicles. CNG has only been popular in light-duty vehicles due to the low energy density of gaseous NG, which gives low autonomy, whereas by storing NG in liquid form vehicles can increase their autonomy by up to $1100 \mathrm{~km}$ [6]. Recent studies suggested that LNG use in heavy duty vehicles (HDV) has the potential to reduce environmental impacts and noise in cities, in addition to the maturity of the technology, energy resource availability and clear interest of the EU in supporting the LNG adoption [7].

The use of NG in vehicles is encouraged by the benefits of reducing local air pollution, resources availability, the existence of distribution infrastructure and relatively lower prices than petroleum fuels [8].

Regarding the GHG emissions, the use of CNG in light vehicles reaches up to the $25 \%$ reduction in $\mathrm{CO}_{2}$ equivalent emissions in its lifecycle comparing to those fed by gasoline. Fed with LNG trucks can achieve low emissions without excessive and expensive emission control equipment as required by diesel engines. The process of production of LNG requires natural gas first dried and then submitted to the removal of hydrocarbons, sulphur and $\mathrm{CO}_{2}$, what gets a high-purity methane $(98 \%)$; therefore LNG vehicles produce even lower quantities of polluting emissions than CNG vehicles [9]. This decrease is even greater when compared with diesel vehicles: $80 \%$ less carbon monoxide, $70 \%$ less NOx and $45 \%$ less unburned hydrocarbons ( $\mathrm{HC}$ ). With respect to diesel, total of $\mathrm{CO}_{2}$ equivalent $\mathrm{GHG}$ emissions reduction is a $15-18 \%$, while solid particles (compared to diesel fuel with low sulphur content), it is more than $97 \%$ [10].

Finally, the use of NG in road transport presents as an added bonus considerable economic savings, because of the lower price of natural gas when in general compared to diesel. For instance, in Spain, savings between $21 \%$ and $34 \%$ per travelled kilometre have been estimated for intercity road freight transport meaning that the extra investment for the natural gas technology investments can be amortized over the course of one year [11].

Despite the technical feasibility of the NG as transport fuel has been widely demonstrated, up to date there has been a weak growth of the use of natural gas for road transport. Three barriers have been identified: the high cost of vehicles, the low level of consumer acceptance and the scarcity of refueling stations. The clean fuel strategy launched by the European Commission [2] and the 2014/94/EU Directive [12] are aimed to encourage the use of alternative fuels by means of the installation of a network of refuelling station through Europe.

But even though the full integration of the natural gas in road transport would lead to a reduction of the environmental impacts of the sector, it would not completely solve its share of responsibility to global warming and the depletion of resources. In the medium to-long term, natural gas of fossil origin must make way to sustainable fuels.

The generation of synthetic natural gas based on renewable energy and neutral in $\mathrm{CO}_{2}$ could be the solution.

In the last years, Power to Gas has been proposed as a very promising and versatile technology that converts electricity into synthetic natural gas via the methanation of $\mathrm{CO}_{2}$ together with $\mathrm{H}_{2}$ from water electrolysis [13,14]. The energy content of the produced methane comes from the primary source for power generation (renewable energy in a sustainable scenario) and it is possible to produce a fuel which does not increase net GHG emissions into the atmosphere if the required $\mathrm{CO}_{2}$ is captured from an existing source $[15,16]$.

The process was originally developed by the German institutes ZSW (Zentrum für Sonnenenergie- und Wasserstoff-Forschung Baden-Württemberg), and IWES (Fraunhofer 
Institute for Wind Energy and Energy System Technology) and there are currently 30 demonstrating plants in Europe [17].

In practice, both existing and projected PtG facilities integrate electrolyser with a wind or photovoltaic installation, but PtG may be used to store surplus or curtailed electricity whilst converting to a gas vector [18]. In any case, this technology would allow the connection between electric and gas network thus increasing the flexibility of the energy supply system [19].

Although this would be also true as for the hydrogen production [20], distribution and use of methane is far more readily available than hydrogen based on the current infrastructure.

Economic related barriers such as the large required investments could be overcome if the $\mathrm{PtG}$ process is seeing as a new concept of renewable energy and $\mathrm{CO}_{2}$ hybrid storage. Symbiosis of industrial sectors through optimization of their waste streams of matter and energy could increase the global efficiency, improve the resource use, and reduce the investment on new equipment. Some of the synergies of these hybrid systems are already being tested under real conditions (e.g. PtG-Amine scrubbing, PtG-wastewater treatment) while others have been studied through numerical simulations for instance PtG-oxyfuel combustion or PtG-Electrochemical hybridization [21].

According the German Federal Ministry of Transport and Digital Infrastructure [22] the development of business models as a step of preparing the markets and synergy with other energy sectors is one of the priority fields of action for the deployment of the PtG in the transport sector.

This paper identifies the possibilities that PtG technology offers for the production of sustainable methane and the existing potential for the symbiosis of the power and the transport sector.

A small facility for the in-situ generation of synthetic natural gas from renewable electricity and $\mathrm{CO}_{2}$ from transport emissions then consumed in the vehicles of a road freight company is used as base case to assess the economic viability of the gas from different electricity origins and at different production scales. In addition, the GHG reduction that could be achieved by the use of synthetic methane as a substitute for diesel transport fuel is assessed.

\section{CASE STUDY}

The PtG process is conceptually explained as follows: renewable electricity is converted to fuel gas by means of electrolysis, storing electrical energy in form of hydrogen. Oxygen is also obtained as by-product from the electrolyser. Then, the generated hydrogen is combined with carbon dioxide to produce methane through the Sabatier reaction:

$$
\mathrm{CO}_{2}+4 \mathrm{H}_{2} \leftrightarrow \mathrm{CH}_{4}+2 \mathrm{H}_{2} \mathrm{O} \quad \Delta \mathrm{H}_{298 \mathrm{~K}}=-165 \mathrm{~kJ} / \mathrm{mol}
$$

Many studies consider the use of surplus or curtailed renewable power [14] from existing installations and the total $\mathrm{H}_{2}$ produced is modelled based on the obtainable electricity [23].

The availability of a suitable source of $\mathrm{CO}_{2}$ can be considered as the main limiting factor for promoting $\mathrm{PtG}$, since it reduces the possible geographic sites for a wide deployment of this technology [24]. Biogas plants, waste managers, energy intensive industries and power plants are the largest $\mathrm{CO}_{2}$ sources and the most interesting partners for integration with $\mathrm{PtG}$ [25]. In the transport sector, carbon capture and storage (CCS) into light vehicles has been also focused. Post-combustion-capture technologies has been identified as the most easily adapted for use with the existing fleet of internal combustion engines [26]. 


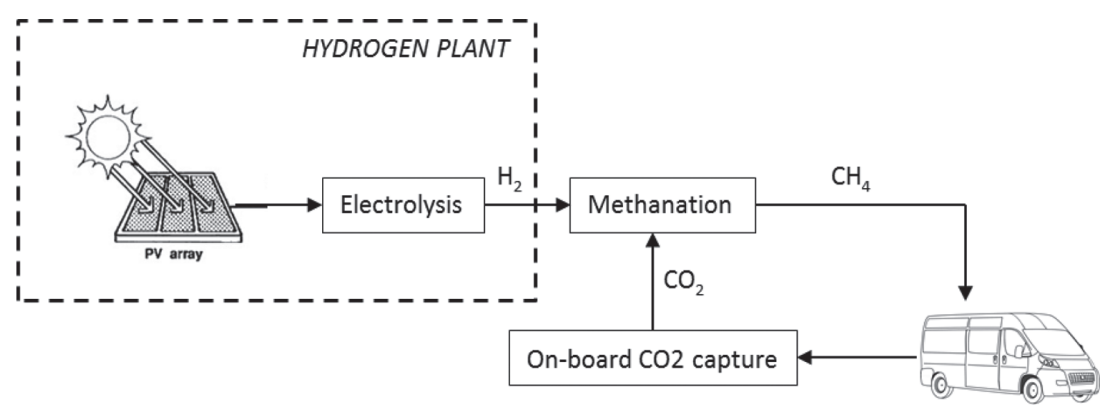

Figure 1: Scheme of the installation for SNG production.

The case under study is based on an isolated installation for the production of renewable and neutral synthetic natural gas in the headquarters of a road freight transport company in Spain.

As shown in Fig. 1, the installation consists of an electrolytic hydrogen production plant and a TREMP methanation plant where hydrogen and $\mathrm{CO}_{2}$ react to produce synthetic methane. In the present study, an isolated PV installation is included in order to assure the renewable origin of the electricity that is consumed in the electrolyser.

Even though $\mathrm{CO}_{2}$ could be provided by other sources, it would be more difficult to demonstrate the neutrality in terms of GHG which is one of the goals for this study. Then it is considered that $\mathrm{CO}_{2}$ derives from the exhausted gases of the vehicles properly separated.

Finally, the produced gas is supposed to be consumed by the company's own vehicles that operate currently with fossil natural gas.

Considering Sabatier reaction and combustion reaction for the methane:

$$
\mathrm{CH}_{4}+2 \mathrm{O}_{2} \rightarrow \mathrm{CO}_{2}+2 \mathrm{H}_{2} \mathrm{O}
$$

the volume of $\mathrm{CO}_{2}$ emitted is equal to the volume previously fixed during the methanation process.

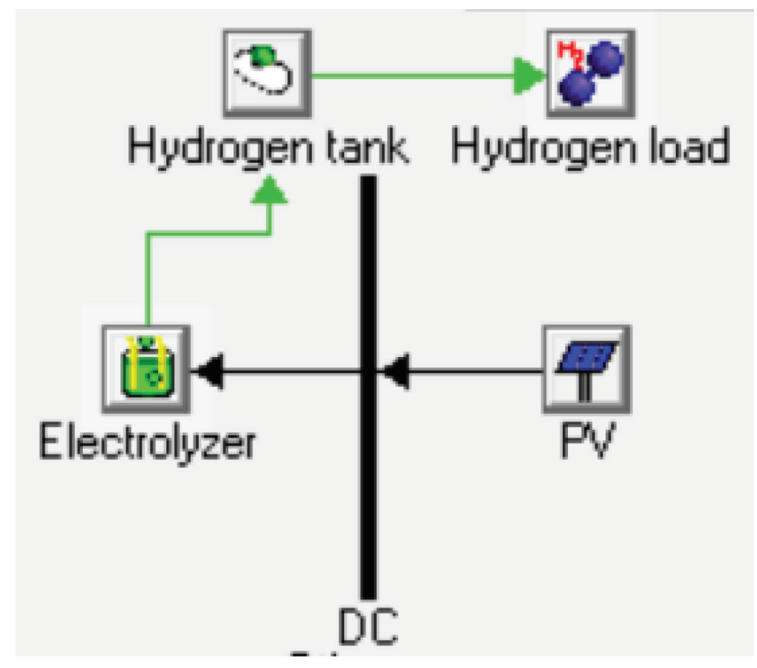

Figure 2: Schematic of the hydrogen plant. 


\section{METHODOLOGY AND RESULTS}

The first step is analysing the activity and the fleet owned by the company in order to estimate the amount of natural gas needed to a reliable and stable delivery over time. The natural gas consumption determines the hydrogen and $\mathrm{CO}_{2}$ demand as according the Sabatier reaction, four times of $\mathrm{H}_{2}$ and one times of $\mathrm{CO}_{2}$ in volume are required for the production of one volume of $\mathrm{CH}_{4}$.

The annual consumption of SNG is estimated considering the technical specifications of the natural gas fuelled vehicles that are owned by the company. One of these vehicles consumes $4.3 \mathrm{~kg}$ of CNG per $100 \mathrm{~km}$. Considering a 1.3 correction factor (for efficiency losses due to the CCS system), $200 \mathrm{~km}$ distance travelled daily and 260 labour days, the vehicle would consume $2900 \mathrm{~kg}$ of synthetic natural gas per year or $11.18 \mathrm{~kg}$ per day. It is assumed that natural gas is fuelled to the vehicle from 6 to $8 \mathrm{AM}$.

The second step is studying the viability of the hydrogen plant in the considered location which requires optimizing the size and number of the system components. As shown in Fig. 2, the size of the PV system, electrolyser and hydrogen storage tank must be determined in this case to ensure that the plant is able to meet the required hydrogen load at the lowest possible cost. The optimization software used for this work is the Hybrid Optimization Model for Electric Renewables (HOMER) from the National Renewable Energy Laboratory (NREL), which was freely available at the moment of the estimations. HOMER is a tool that implements comparative economic analyses on distributed generation power systems. Inputs to HOMER include load data, renewable resource data, system component specifications and costs, and various optimization parameters. HOMER performs an hourly simulation of every possible combination of components entered and ranks the systems according to user-specified criteria, such as cost of energy or capital costs.

To obtain the input data for HOMER, information of the hydrogen plant components was collected from research literature and manufacturers to obtain an estimation of hydrogen system costs and efficiencies. Also collected are the load and resource time series data and information necessary to model the systems.

The operating principle is to use a PV system to directly supply the electrolyser that meet the hydrogen load. When excess PV energy is available, the generated hydrogen is stored in a tank.

Hydrogen load data were estimated considering the SNG consumption and the conversion rates according the Sabatier reaction. A production of around $1454 \mathrm{~kg}$ of hydrogen per year or $5.59 \mathrm{~kg}$ per day is needed. It is assumed that hydrogen plant is operated from 7 AM to 3 PM.

Solar radiation and clearness data for the installation site were for GMT Time Zone. The annual average global radiation is $5.507 \mathrm{kWh} / \mathrm{m}^{2} /$ day and the annual average clearness index is 0.573 .

This scenario was modelled with PV panels fixed at a slope of $30^{\circ}$ and lifetimes were assumed to be 20 years.

In HOMER, a solution is a particular hybrid system configuration. As HOMER searches for the optimal hybrid system design, it typically evaluates a high number of solutions. HOMER performs an hourly time series simulation of every solution and eliminates solutions that cannot meet the required load. For the case under study, HOMER examined the 1080 solutions possible by combining components.

The least-cost technically viable solution consists in a PV installation of $100 \mathrm{~kW}$, one electrolyser of $50 \mathrm{~kW}$ and compressed gas storage with $100 \mathrm{~kg}$ of capacity. Next Table 1 summarized the main costs of the hydrogen installation. 
Table 1: Cost for the hydrogen production plant.

\begin{tabular}{lll}
\hline Initial capital & Operating cost $(\$ / y r)$ & Total NPC \\
\hline$\$ 544206$ & 45982 & $\$ 1132015$ \\
\hline
\end{tabular}

With a total electrolyser production of $1434 \mathrm{~kg}$ of hydrogen per year, the levelised cost of hydrogen is $60.9 \$ / \mathrm{kg}$.

Regarding the availability of $\mathrm{CO}_{2}$ it is considered the use of those emitted by the vehicle that is around $8000 \mathrm{~kg}$ per year.

Onshore capture methods with amines have been tested only for their use in ships, including compression process for convenient and efficient transportation and storage. However, if compression methods are applied on engines mechanically, then serious problems arise, such as power penalties, space requirements for storage, and safety issues.

Several author have set that the energy consumption required to attain concentrated $\mathrm{CO}_{2}$ streams leads to efficiency penalties that range between 9 and 12 efficiency points, and the associated costs may vary from 50 to $90 \$ / \mathrm{tCO}_{2}$, depending on $\mathrm{CO}_{2}$ concentration in flue gas and capture technology [27]. The higher limit has been considered for economic considerations in this paper.

Methanation costs of $10 \$ / \mathrm{kg}$ and $1.01 \$ / \mathrm{t}$ for gas compression are considered [28].

The cost of producing $1 \mathrm{~kg}$ of SNG in the proposed installation is calculated as $40.4 \$$ that is twice as high as the market price for fossil natural gas.

Regarding $\mathrm{CO}_{2}$ emissions, the EU Renewable Energy Directive of 2009 states that biofuel emissions are calculated as zero due to balancing the amount of carbon released with an equivalent amount sequestered, therefore such emissions were not considered. Then, the environmental benefits considered in this paper are the GHG emissions (in carbon dioxide equivalent, $\mathrm{CO}_{2} \mathrm{eq}$ ) saved when the total $\mathrm{CH}_{4}$ produced is used to replace diesel fuel.

Lifecycle assessment results from literature were collected in order to determine GHG emissions in replacing diesel with renewable gas. The "Well to Wheel" life cycle assessment includes emissions associated with fuel production, processing, transportation, distribution and consumption.

The total $\mathrm{CO}_{2}$ eq saved when the total $\mathrm{CH}_{4}$ produced is used to replace diesel fuel is calculated as substituted fuel in $\mathrm{MJ}$ multiplied by the emission factor in $\mathrm{kgCO}_{2} \mathrm{eq} / \mathrm{MJ}$. Considering an emission factor of $2.61 \mathrm{kgCO}_{2} \mathrm{eq} / \mathrm{MJ}$, each vehicle saves around 10 tons of $\mathrm{CO}_{2}$ per year.

Although this paper proposes the integration of renewable energy systems for both transport and decentralized production of fuels as a way to achieve security of supply, fuel costs are quite high but within the limits if $\mathrm{R} \& \mathrm{D}$ is still continuing.

\section{CONCLUSIONS}

This paper has approached the combination of renewable electricity and $\mathrm{CO}_{2}$ sourced from transport emissions in order to provide a source of renewable transport fuel.

The existing potential for the integration of sectors such as energy and transport through optimization of their flows of matter and energy (industrial symbiosis) has been demonstrated.

The obtained results may open new prospects for the development of infrastructure of supply and storage and production distributed synthetic natural gas as alternative fuel, enhancing its availability and promoting their full integration in the transport sector. 
In order to reduce the current costs, the search for innovative solutions that allow adapting the transport infrastructures to the efficient use of alternative energy in order to reduce exploitation costs must be pursued.

\section{ABBREVIATIONS}

BEVs: battery electric vehicles, CCS: carbon capture and storage, CNG: compressed natural gas, CO2eq: carbon dioxide equivalent, EU: European Union, FCEVs: fuel cell electric vehicles, GHG: greenhouse gases, HC: hydrocarbons, HDV: heavy duty vehicles, IWES: Fraunhofer Institute for Wind Energy and Energy System Technology, LNG: liquefied natural gas, NG: natural gas, PtG: Power to Gas, SNG: synthetic natural gas, ZSW: Zentrum für Sonnenenergie- und Wasserstoff-Forschung Baden-Württemberg

\section{REFERENCES}

[1] ETP, "White paper European transport policy for 2010: time to decide. Commission of the European communities," p. 2010, 2001.

[2] European Commission, "Alternative fuels for sustainable mobility in Europe - European Commission," 2013 [Online], available at: https://ec.europa.eu/transport/themes/ urban/cpt_en (accessed 17 July 2017).

[3] EEGFTF, "Future Transport Fuels, Report of the European Expert Group on Future Transport Fuels," Düsseldorf, 2011.

[4] European Environment Agency, "Electric vehicles and the energy sector - impacts on Europe's future emissions — European Environment Agency," 2016 [Online], available at: https://www.eea.europa.eu/themes/transport/electric-vehicles/electric-vehicles-andenergy (accessed 17 July 2017).

[5] Hekkert, M.P., Hendriks, F.H.J.F., Faaij, A.P.C. \& Neelis, M.L., Natural gas as an alternative to crude oil in automotive fuel chains well-to-wheel analysis and transition strategy development. Energy Policy, 33(5), pp. 579-594, 2005.

https://doi.org/10.1016/j.enpol.2003.08.018

[6] DENA, "LNG in Germany: Liquefied Natural Gas and Renewable Methane in HeavyDuty Road Transport," 2014 [Online], available at: http://www.dena.de/en/topics/ energy-efficient-transport-systems.html (accessed 17 July 2017).

[7] Osorio-Tejada, J.L., Llera-Sastresa, E. \& Scarpellini, S., Liquefied natural gas: could it be a reliable option for road freight transport in the EU? Renewable and Sustainable Energy Reviews, 71, pp. 785-795, 2017. https://doi.org/10.1016/j.rser.2016.12.104

[8] Yeh, S., An empirical analysis on the adoption of alternative fuel vehicles: the case of natural gas vehicles. Energy Policy, 35(11), pp. 5865-5875, 2007.

https://doi.org/10.1016/j.enpol.2007.06.012

[9] Chamberlain, G.A., MANAGEMENT OF LARGE LNG HAZARDS, 2006 [Online], available at: http://citeseerx.ist.psu.edu/viewdoc/download?doi=10.1.1.567.7712\&rep $=$ rep1\&type=pdf (accessed 17 July 2017).

[10] Fedorova, E.B., Fedorov, V.V. \& Shakhov, A.D., Promising technology for recovery and use of liquefied natural gas cryogenic engineering, production and use of industrial gases, refrigeration engineering. Chemical and Petroleum Engineering, 45(3), pp. 3-4, 2009.

[11] GASNAM, Estrategia de Impulso del vehículo con energías alternativas (VEA) en España (2014-2020), 2015. 
[12] European Parliament and the Council of the European Union, "DIRECTIVE 2014/94/ EU OF THE EUROPEAN PARLIAMENT AND OF THE COUNCIL - of 22 October 2014 - on the deployment of alternative fuels infrastructure -," 2014.

[13] Götz, M., Lefebvre, J., Mors, F., Koch, A.M., Graf, F., Bajohr, S., Reimert, R. \& Kolb, T., Renewable Power-to-Gas: a technological and economic review. Renewable Energy, 85, pp. 1371-1390, 2016. https://doi.org/10.1016/j.renene.2015.07.066

[14] Rönsch, S., Schneider, J., Matthischke, S., Schlüter, M., Götz, M., Lefebvre, J., Prabhakaran, P. \& Bajohr, S., Review on methanation - From fundamentals to current projects. Fuel, 166, pp. 276-296, 2016.

https://doi.org/10.1016/j.fuel.2015.10.111

[15] Streibel, M., Nakaten, N., Kempka, T. \& Kühn, M., Analysis of an integrated carbon cycle for storage of renewables. Energy Procedia, 40, pp. 202-211, 2013.

https://doi.org/10.1016/j.egypro.2013.08.024

[16] Kühn, M., Nakaten, N., Streibel, M. \& Kempka, T., $\mathrm{CO}_{2}$ geological storage and utilization for a carbon neutral "power-to-gas-to-power" cycle to even out fluctuations of renewable energy provision. Energy Procedia, 63, pp. 8044-8049, 2014. https://doi.org/10.1016/j.egypro.2014.11.841

[17] Bailera, M., Lisbona, P., Romeo, L.M. \& Espatolero, S., Power to gas projects review: lab, pilot and demo plants for storing renewable energy and $\mathrm{CO}_{2}$. Renewable and Sustainable Energy Reviews, 69, pp. 292-312, 2017.

https://doi.org/10.1016/j.rser.2016.11.130

[18] Estermann, T., Newborough, M. \& Sterner, M., Power-to-gas systems for absorbing excess solar power in electricity distribution networks. International Journal of Hydrogen Energy, 41(32), pp. 13950-13959, 2016.

[19] Qadrdan, M., Abeysekera, M., Chaudry, M., Wu, J. \& Jenkins, N., Role of power-to-gas in an integrated gas and electricity system in Great Britain. International Journal of Hydrogen Energy, 40(17), pp. 5763-5775, 2015.

https://doi.org/10.1016/j.ijhydene.2015.03.004

[20] Emonts, B., Schiebahn, S., Görner, K., Lindenberger, D., Markewitz, P., Merten, F. \& Stolten, D., Re-energizing energy supply: electrolytically-produced hydrogen as a flexible energy storage medium and fuel for road transport. Journal of Power Sources, 342, pp. 320-326, 2017. https://doi.org/10.1016/j.jpowsour.2016.12.073

[21] Bailera, M., Espatolero, S., Lisbona, P. \& Romeo, L.M., Power to gas-electrochemical industry hybrid systems: a case study. Applied Energy, 202, pp. 435-446, 2017. https://doi.org/10.1016/j.apenergy.2017.05.177

[22] Bünger, U., Landinger, H., Pschorr-Schoberer, E., Schmidt, P. \& Weindorf, W., Powerto-Gas (PtG) in transport Status quo and perspectives for development. Naumann (dbfz); A. Lischke (DLR) Munich, 2014 [Online]. Available at: http://www.lbst.de/ressources/ docs2014/mks-studie-ptg-transport-status-quo-and-perspectives-for-development.pdf. (accessed 17 July 2017)

[23] Vo, T.T.Q., Xia, A., Wall, D.M. \& Murphy, J.D., Use of surplus wind electricity in Ireland to produce compressed renewable gaseous transport fuel through biological power to gas systems. Renewable Energy, 105, pp. 495-504, 2017.

https://doi.org/10.1016/j.renene.2016.12.084 
[24] Schneider, L. \& Kö, E., The geographic potential of Power-to-Gas in a German model region - Trier-Amprion 5. Journal of Energy Storage, 1, pp. 1-6, 2015. https://doi.org/10.1016/j.est.2015.03.001

[25] Sterner, M., Institut für Solare Energieversorgungstechnik., and Institut für Elektrische Energietechnik Rationelle Energiewandlung., Bioenergy and renewable power methane in integrated $100 \%$ renewable energy systems: limiting global warming by transforming energy systems. Kassel University Press, 2009.

[26] Sullivan, J.M. \& Sivak, M., Carbon capture in vehicles: a review of general support, available mechanisms, and consumer acceptance issues. University of Michigan Transportation Research Institute, Ann Arbor, 2012.

[27] IPCC, IPCC Special Report on Carbon Dioxide Capture and Storage. Prepared by Working Group III of the Intergovernmental Panel on Climate Change [Metz, B., O. Davidson, H. C. de Coninck, M. Loos, and L. A. Meyer (eds.)]. Cambridge University Press, Cambridge, 2005.

[28] E\&E Consultant Environement Energie, "Etude portant sur l'hydrogène et la méthanation comme procédé de valorisation de l'électricité excédentaire," 2014. [Online]. Available at: http://www.grtgaz.com/fileadmin/engagements/documents/fr/Power-toGas-etude-ADEME-GRTgaz-GrDF-complete.pdf (accessed 17 July 2017). 